\title{
Digital Inclusion Without Social Inclusion: The consumption of information and communication technologies (ICTs) within homeless subculture in Scotland
}

\author{
Claire Bure \\ University of Edinburgh Science and Technology Studies, Msc Programme < claire.bure@ gmail.com>
}

\begin{abstract}
This pilot study examined how homeless people in central Scotland integrate and appropriate mobile phones and the Internet into their everyday lives, and the meanings these information and communication technologies (ICTs) come to hold for them. It was found that 'digital inclusion' does not necessarily lead to 'social inclusion' into mainstream society, since homeless individuals tend to use ICTs in ways that reinforce the patterns and practices of their subculture. There is no standard way of making use of technologies. Many homeless people thereby remain socially excluded in numerous ways despite their somewhat regular use of ICTs. It also emerged that mobile uptake can actually be more 'inclusive' than Internet uptake.
\end{abstract}

\section{Introduction and Background}

Technology is an integral part of modern society and social change. It plays both a part in shaping, and is shaped by, the patterns and practices of everyday life. In order to understand more fully how information and communication technologies (ICTs) influence social change, it is necessary to study how they are integrated and appropriated into the everyday life of humans (Lie \& Sørensen, 1996). This relationship should be studied with respect to all social groups, including homeless people.

Contemporary debates have focused on whether the application of ICTs will either 'bridge' the digital divide between those who have access and those who do not, or whether it will further the social inequalities between 'haves' and 'have-nots' (Henwood et al., 2000). However, these arguments are often technologically determinist, stemming from a perception that the application of technologies will lead to specific uses and outcomes. The complexity of the routes to social inclusion, however, should not be underestimated. The digital divide debate also tends to concentrate on Internet access, when in reality mobile phones are becoming one of the key technologies of connectivity (Fortunati \& Manganelli, 2002). Nevertheless, it is clear that inequalities prevail between the 'information rich' and 'information poor' and these should be seen as a continuum that is spatially and temporally contingent (Richardson \& Le Grand, 2002). It is therefore important to study the implications and consequences of homeless people's access, use and attribution of meanings to ICTs in relation to processes of social inclusion.

\section{Homeless People as Socially Excluded}

Homeless people can be seen as being socially excluded in a number of ways; the deprivations they face being experienced as temporary, cyclical or even long-term events (Forrest, 1999). Even people who are labelled as excluded will themselves point out that social exclusion involves a lack of participation in 'normal' or socially-valued activities, with low levels of consumption of public goods and services (Richardson \& Le Grand, 2002). Additionally, the experience of social exclusion can involve a lack of 
community or social interactions, poor links to formal (rather than informal) social networks and exclusion from public services (Richardson \& Le Grand, 2002).

Although a contested concept, three points need to be kept in mind when investigating 'social exclusion'. First, people who are socially excluded should be thought of in terms of groups, such as communities or neighbourhoods (rather than individually), within a particular place and time (Atkinson, 1998). Second, exclusion should be seen as an act resulting not from a single factor, but rather from a mixture of factors, which can be attributed to either socially excluded people themselves or problems in wider social and economic structures. Last, people can be socially excluded in a variety of ways and for a number of reasons. That is, "people are excluded not just because they are currently without a job or income but because they have little prospects for the future" (Atkinson, 1998).

\section{Homelessness as a Subculture}

Homeless population statistics are difficult to estimate (Shaw et al., 1996). Being homeless does not always imply 'rough sleeping'; that is, sleeping outside in public or private areas generally not designed for sleeping. In fact, only proportionately few homeless people sleep rough (Edinburgh Cyrenians, 2001). The subculture of homelessness is often characterized by recurring problems of criminal activity (Ballintyne, 1999) and an alcohol or drug dependence (or 'using'). These activities can either be causes or effects of homelessness (Shelter Scotland) ${ }^{1}$. Additionally, higher rates of mental illness and physical health problems are prevalent among homeless populations (Glasser \& Bridgman, 1999). Many factors create vulnerabilities that can lead to homelessness, including: low levels of education; unemployment; a lack of supportive social networks; background (such as a difficult childhood) and learning disabilities (Edinburgh Cyrenians, 2001). Common triggers can include: family disputes, a relationship breakdown, domestic violence or abuse, eviction, debt, or leaving an institution such as prison (Edinburgh Cyrenians, 2001).

The lifestyle of homeless people is typically transient, nomadic and built on the immediate gratification of needs, so activities tend to be planned on a minute-to-minute basis. The subculture of homeless people is often described - but ill-defined - as 'chaotic'. This is a colloquial term used to describe a lifestyle full of unpredictable events. Generally, homeless people are vulnerable individuals who lack independent living skills, or the ability to sustain a tenancy. They may become "mentally unstuck" after only two or three days of experiencing homelessness. After this short period, an individual begins to cope and builds relations with other people living on the streets. That person can learn quickly where to find food, clothing and laundry facilities, and where the 'begging patches' are if they decide to beg for money (Ravenhill, 2000). However, it is important to note that not all homeless individuals fit this standard profile.

To clarify how homeless people tend to 'fit' within normative society, it is useful to employ the concept of 'social inclusion'. For the purposes of this study, social inclusion can be understood as it is commonly defined within social inclusion literature, as well as from the perspective of support service organisations and socially excluded groups ${ }^{2}$. The elements of social inclusion involve: inclusion into social support networks; social, economic, and institutional stability (through access to services); public participation in mainstream activities; and individual agency (having life-skills and motivation to be selfsufficient) (Ferlander \& Timms, 1999). Also, inclusion is composed of elements which are shaped and determined by multiple groups of people (Thomas \& Wyatt, 2000).

The concept of digital inclusion helps us to understand the routes to social inclusion in relation to how people appropriate and use information and communication technologies. Digital inclusion involves not just access to information and communication technologies (Thomas \& Wyatt, 2000) but also 'ICT capability': the necessary skills to use the ICT in question, as well as the knowledge about when and how to use it, and the confidence to do so (Faulkner \& Kleif, 2003a). Digital inclusion is more than just the acquisition of information resources; the everyday social relations that are built and maintained using ICTs are also important. Both social inclusion and digital inclusion are concepts that hold normative

\footnotetext{
${ }^{1}$ Homelessness in Scotland, Shelter Scotland webpage, which can be found at: http://scotland.shelter.org.uk/policy/policy-421.cfm/plitem/101

${ }^{2}$ Support service organizations are those voluntary or involuntary organizations that are geared towards helping 'disadvantaged individuals', or homeless people, within the context of this study.
} 
connotations, where inclusion is seen as a goal towards which policy initiatives should aspire. For example, a report by the Scottish Executive entitled 'Digital Inclusion: Connecting Scotland's People' (2001), asserts: "A digitally-inclusive Scotland will ensure more equal, effective and beneficial access for all people to the digital technologies and Web facilities that benefit them in their day-to-day lives."

\section{Research Design and Methodology}

This pilot study investigated how homeless people come to use and impart meaning on ICTs in their everyday lives, and how this may influence integration into mainstream society. In so doing, more insight is provided on the relationship between the concepts of digital inclusion and social inclusion. A total of 16 men and women were interviewed in Edinburgh and Glasgow, Scotland, cutting across different ages, socio-economic backgrounds, experiences and ideas, and 'types' of homelessness ${ }^{3}$. Respondents included five service agency workers, ten homeless and ex-homeless individuals, and one ex-homeless woman who also worked as an outreach worker ${ }^{4}$. Data were gathered in nine informal, reflexive, semi-structured interviews and focus groups. Open-ended questions focused on: the characteristics of homeless subculture, organizational services and access to them, issues of use and access to mobile phones and the Internet, and the relations between these issues. Although it is difficult to generalize qualitative research findings to broader contexts - particularly with a small number of respondents - this methodology can be very useful for studying particular groups of people, including homeless people (Banyard \& Miller, 1998). It should be kept in mind that the experiences and situations of participants in this study do not necessarily represent the nature of daily life for all homeless people.

The interpretation of findings was informed by a social construction of technology perspective, which recognizes that technologies are socially constructed by the broader social, political, economic and cultural context (Bijker et al., 1987). Therefore, in order to fully understand the relevance of ICTs for homeless people, the uses and meanings of mobile phones and the Internet were placed within the various contexts of homeless subculture. From the social constructivist perspective stems a social shaping of technology perspective, which holds that technologies profoundly influence human activities; and humans, in turn, influence how technologies develop and come to be used (MacKenzie \& Wajcman, 2002). In addition, findings were interpreted in light of existing relevant theoretical frameworks. These are presented within the following sections.

\section{The Consumption and Domestication of Technologies in Everyday Life}

The study of how we engage with technologies, the meaning they take on, and how they shape our lives is the study of the consumption of technology (based on a social shaping approach). Technology consumption needs to be contextualized within 'everyday life', which can be been defined as regular rather than daily - production and reproduction of human social patterns (Lefevbre, 1971). Through the study of technology in everyday life it can be seen that technology is non-standardizing: it does not drastically change our lifestyle patterns, but rather fits in with them (Lie \& Sørensen, 1996).

The study of the domestication of technology is the study of the process of the acquisition of a technical artefact, new or old, within the domestic sphere of the everyday life of an individual or group of individuals, and the subsequent meaning and use it takes on. Domestication studies look at how technologies - and particularly ICTs - are a part of the relationship between private households and public spaces (Silverstone, et al., 1994). The Theory of Domestication outlines four related phases in the dynamic process of technology domestication: appropriation, objectification, incorporation and conversion (Silverstone et al., 1994). The first phase, appropriation, is the possession or ownership of the artefact. This is the point at which the artefact moves from being a commodity that is exchanged, to the owner's

\footnotetext{
${ }^{3}$ A summary of each interview can be found in the Appendix.

${ }^{4}$ The experiences of more than the 16 people interviewed are represented in this research, since homeless and ex-homeless respondents alike shared information about their family, friends, and acquaintances; and service agency workers shared information about their clientele. This gave more people a 'voice', including those who were sleeping rough.
} 
possession, thereby giving it significance. Objectification occurs when the artefact is used and displayed in the household, not only defining the household's place in a greater public context (such as status), but also helping to construct that new environment. Incorporation is the phase during which technologies are used in everyday life, where its level of functionality depends on how it is incorporated into everyday life. Last, conversion looks at how the 'enclosed' technologies in the household, and the meanings and uses they hold, fit into wider public spaces (Silverstone et al., 1994).

Due to the blurring of both spatial and temporal boundaries between the 'home' and the outside world, the investigation of the place of technology in everyday life needs to be broadened from using the household as a single unit of analysis within domestication studies to a 'local' setting (Stewart, 2003). The Theory of Domestication can be broadly applied to explain how mobile phones and the Internet are appropriated, objectified, incorporated and converted by individuals who are homeless. Its use in this manner also reveals that the theory needs to be adjusted to 'include' minority groups and how they make use of technologies, including contexts outside of the home.

From the findings of this study it appears that homeless people appropriate ICTs in ways that are relevant to their own lives, such that these technologies reinforce the patterns and practices of their lifestyles. Mobiles, more so than the Internet, tend to be used in ways that become incorporated into, and facilitate various activities prevalent in homeless culture, including both practical issues (such as drugs and crime) as well as symbolic issues (such as reliance, safety and status).

\section{Domestication of the Internet by Homeless People}

With respect to the first phase of domestication, appropriation, it seems that many younger homeless individuals (approximately under the age of 30), and some older ones, access the Internet somewhat regularly in Edinburgh and Glasgow. Free access is limited to a small number of public sites, or to computers at family or friends' houses. However, there is an internet café for homeless people in Glasgow, specifically created in response to a request by homeless drop-in clients themselves for free Internet access. Those who do gain access relatively regularly are generally knowledgeable about free services available in the city, and information about these places tends to spread via word-of-mouth among homeless individuals. Homelessness support workers, in contrast, tend to have little working knowledge about these free Internet access points, and neither do they tend to actively encourage access.

Objectification, the second phase of domestication, can only partially be applied to homeless persons' use of the Internet since their use is limited to a small number of public Internet terminals, and therefore they have little control over its spatial and temporal uses. This emphasizes the necessity for homeless people to turn to public spaces for the majority of their needs. Perhaps because the Internet is generally accessed in public spaces, issues of identity and status (such as the level of ICT capability they are able to draw on) also become more public for homeless people.

Third, homeless individuals incorporate ICTs into their lives in a number of ways. For those homeless people who do access the Internet, the uses vary widely from using email and chatrooms to communicate, to using it for entertainment purposes or as a resource for information, making the extent to which it actually 'integrates' into their subculture a questionable issue. However, how certain tasks are completed depends on the mental or emotional state of the individual. For example, one young homeless respondent who admitted that he was a regular drug user claimed that he had five or six (he couldn't be sure) email addresses because he could rarely remember his passwords due to his own forgetfulness and irregular access to the Internet.

With respect to the last phase of domestication, conversion, it is difficult to make any distinctions between how homeless people 'convert' computers into their own lives, compared to those who live in permanent tenancies. This is again because homeless people tend to be limited to using the Internet at a public terminal, or at a friend or family member's home. Thus the computer itself can never fully be converted into a homeless individual's personal life-space.

\section{Domestication of Mobile Phones by Homeless People}

Findings from the study made it evident that many, if not most, homeless individuals have access to a mobile phone in central Scotland. Mobile phones are much more commonly used within homeless subculture than the Internet. Another study focussing on Western European countries also found mobile 
phone uptake to be more 'inclusive' than Internet uptake: there is a lower tail-off in use for those with lower socio-economic status and education levels, and the gender gap between users is smaller (Sørensen, 2002). Despite variations in access and use among individuals, younger users seemed much more likely to gain access than older ones. The method of payment for homeless people's mobile phones is virtually always 'pay-as-you go' rather than contract billing, since a permanent address is often needed for the latter, and payments need to be made consistently, something which is often very difficult for a homeless person, due to their tendency to be economically unstable.

Mobile phones are easily accessible because they can be bought for relatively low prices at a number of places, such as pawnshops and flea markets, or they may be gifts from friends or family members who want to keep in touch. Some homeless people claim to find mobiles, trade other goods for them, or admittedly resort to illegal methods of access, such as theft. Alternatively, some homeless clients receive mobile phones from their outreach workers, who wished to keep in contact more easily. This was not a formally recognized means for access, and neither was it an activity that was acknowledged among service organizations. While policy justifications were not in place for mobile distribution by social service agencies, it did seem that homeless outreach workers had a significant level of power to make the decision to provide a mobile to a client, based on their own knowledge of 'how that person was doing.' More research would be needed to see if this model has been replicated outside of central Scotland, and the consequences it holds for social service delivery. The implications of homeless clients receiving mobile phones are discussed in a later section.

The second domestication phase, objectification, is more easily applied to homeless people's use of mobile phones than the Internet because they are more transportable technologies. The mobile phones that homeless people tend to use are older and larger, since those are cheaper and easier to access. Interestingly, lower mobile value is not necessarily seen as undesirable, since it ensures the devices are less readily stolen. In this sense, the characteristics of the technology fit in with and are embraced by homeless subculture in a way that is different from the typical end-user targeted by technology developers.

Mobile phones are much more easily incorporated into everyday life by homeless people than the Internet. Certainly not all homeless people are drug users, but for those who are, mobiles have been found to be useful tools for obtaining or dealing drugs. Because of the potential for instant communication, drugs can be sold, bought or traded more quickly and easily, independent of the physical location of the interested parties. This can make curbing a drug dependency or addiction more difficult because it may be difficult to reduce contact with other users or dealers if working to become 'clean' (or drug-free).

Mobile phone use was also linked with committing crimes, since it provides instant communication routes that can help prevent individuals from getting caught. As described by one ex-homeless interviewee, some homeless people may use their mobiles to contact:

Mainly their dealers, or their mates around the corner, if they're tryin' to get into somewhere. You know what I mean? Look out for the cops, you know, in the case of rape 5 . Just like that, you know... Basically if I'm across the road, and this place is gettin' broken into, right? And it's my mate that's doin' it, and I can see the cops comin' and I'll be ringin' him and goin': 'cops are on their way, get yer - you know - get out, quick!'. That sorta thing. Or when I'm dealin' and I want a 10-inch bag o' smack or somethin' like that. That's mostly what they use it for, but I use mine for 'personal use'... for chaos, you know, so what?

It is perhaps surprising the extent to which technology use can stray so far from intended uses (such as drug and crime-related activities), which is also a primary finding from the 'Social Learning in Multimedia' project (Williams, Slack \& Stewart, 2000). Clearly, a more realistic understanding of technologies and their effects should be taken.

Last, mobiles become easily 'converted' into homeless subculture because, as has been shown, these ICTs may allow for homeless people to 'hide' from undesirable situations by using them as a warning tool. On the other hand, it may also be possible that homeless individuals find it more difficult to hide after a crime or misdeed has been committed, since they can more easily be contacted via mobile phone and are

\footnotetext{
${ }^{5}$ If activities as serious as rape are facilitated through mobile telephony, this clearly points to the need for more research on the unintended consequences of communication technologies.
} 
thereby put in a position to be more answerable for their own behaviour. Similarly, frustration at being unable to 'escape' from the demands that arise from mobile phone use is common to many mobile users including those who are not homeless (Katz \& Aakhus, 2002).

Mobiles display status and identity characteristics through their use, which are varying and fluid in character since they are open to multiple interpretations. Mobile phones seem to carry relevance as a status symbol for all homeless people whether this is favourable or not. This can have implications in other areas of life for homeless people, because as one outreach worker described: if someone sees a homeless individual with a mobile, especially someone who is sleeping rough, it may lead to the assumption that they are "fakes" and cannot be homeless. Assumptions seem to run deep that mobiles are more highly used by those with a higher socio-economic status (McIntosh \& Erskine, 1999).

Although no strict generalizations can be made, those homeless people experiencing more chaos in their lives tend to use their mobiles in different ways - particularly more sporadically and less dependably from those who are more stable. It seems that perceptions of ICT functionality are lower for those who lead more chaotic lives. One outreach worker claimed that the Internet really seems to be a tool used by those who are more in control of their situations, whereas mobiles seem to be appropriated by any 'type' of homeless person, involving a variety of meanings and uses. She claimed that people who are in tenancies tend to hold on to their mobiles for a longer period of time, since those who live in tenancies tend to be more socially and economically stable, and tend to take better care of their mobile phones.

\section{Mobile Phones, the Internet and Their Varying Meanings}

Livingstone's (1994) theoretical perspective is useful for making sense of how homeless people impart meaning on ICTs. This theory identifies four constructs which characterize how people generally attribute meaning to a domestic technology. These include: necessity, control, functionality and sociality. That is, technologies are seen as necessary or essential tools; they allow people to control their situations (such as activities, time and other people); they may have various functions or utilities, and may allow for enhanced sociality and privacy. With reference to the first construct, homeless people's perceived necessity of having a mobile seems to be higher than for the Internet (despite variation between individuals). According to one outreach worker, this is because:

In some senses, what relevance has [the Internet] got for people who are scrounging around, perhaps for a cigarette or another bloody can of beer or another hit or are looking for some food or accommodation ... things are often so stressful, and can be so chaotic, but at that point you really want somebody else [where a mobile might be more useful for contacting somebody for help].

Second, access and use of mobile phones and the Internet - particularly for communication purposes may allow homeless individuals a higher capacity to control various aspects of their own lives. The potential to gain immediate contact with another person also has significant personal safety implications, since help is deemed to be more directly available with a mobile, allowing some individuals more physical freedom. Also, from a support workers' point of view, being in contact with a client via mobile allows them to "see whether [their client] is safe, or even alive." A parallel can be drawn here to parents who have provided their children with mobile phones so that they can monitor their children's activities. For example, when a parent is working but their child has leisure time. Mobile phones thereby facilitate the "construction of a safety net" in both cases (Vestby, 1996).

With respect to perceived functionality of ICTs, some homeless people recognize the value, or potential value, of the Internet as a resource, but this does not necessarily lead to active consumption of the technology, due to a lack of ICT capability or access, for example. On the other hand, some homeless people seem to find the Internet an intimidating technology, and fail to see its utility. These varying perceptions may hinge on a number of factors such as confidence, self-esteem and IT skill levels. The functionality of mobiles, on the other hand, differs somewhat from that of the Internet. Mobile phones are perceived by some homeless people as 'cash in the pocket', as a tradable commodity that has ongoing value. One young ex-homeless individual described, "I would trade my phone for some drugs, you know, if it was good quality", emphasizing the relative market value that is placed on the technology. Seemingly, the more chaotic a homeless person's lifestyle, the more likely they are to trade, sell, steal, or lose mobiles and perceive them as tradable commodities since they face higher pressures to satisfy basic needs. One 
related disadvantage to mobiles being lost or stolen, an issue brought up by a number of respondents, is their size: since mobiles tend to be getting smaller, they are becoming easier to lose or have stolen. Mobile size may therefore be related to low levels of socio-economic status and perhaps even identity as a homeless person.

Mobiles (and the Internet to a lesser extent) allow homeless individuals higher levels of sociality and privacy than using publicly accessed ICTs. This allows them to feel more comfortable exchanging personal information over the phone, at more convenient times and therefore more easily. If communication is facilitated in this way, it becomes clear how this can significantly alter an individual's life, and makes the mobile a useful tool. Since the lifestyles of homeless people are often transient and nomadic in nature, having a mobile or an email address allows that person to be contacted, irrespective of their physical location. This can have significant implications for the maintenance of a homeless individual's social networks. ICTs can facilitate contact with friends, family, peers, and support workers, such that they can be in contact more frequently and immediately, depending on how reliably contact can be taken up. Although there are a number of barriers that prevent access and use of mobiles and the Internet, homeless people nevertheless can overcome these barriers to a greater or lesser extent.

It is important to look not only at how and why technologies are used, but also how and why they are not used. For homeless people, this is often a case of exclusion or ambivalence towards the technology in question, rather than active resistance, although the latter may be true in some cases (particularly with respect to the Internet). Homeless people are often 'rejected' or physically excluded from public Internet access points, whether they are free of charge or not, since they are stigmatized by the way they may look or act. For example, homeless people tend to be rejected from public libraries, where free Internet access if often available, because they may try - or be assumed to try - to sleep there. Libraries can thereby become 'enforcers' such as a public library in Alexandria, Virginia (USA) which installed an electronicallycontrolled door and camera outside the men's toilet to discourage bathing or the washing of clothes (Silver, 1996). The context or environment in which an Internet access point is situated, therefore, is crucial in influencing whether homeless people come to use that resource or not. As one outreach worker explained, it is possible for a homeless person to walk past the city library without even noticing its presence because "It's not their stomping ground, really...it's not their frame of reference."

On the other hand, those Internet access points meant specifically for homeless people are not intimidating, but rather welcoming for individuals. With respect to one particular Internet access point in Edinburgh for homeless people, one volunteer worker described, "I think they quite like the fact that it's in a warm, cozy place, and they can just crash and use the printer and scanner." Physical location, therefore, brings with it many social implications (from stigmatization to social acceptance), which affects how that space, including the technologies held within it, come to be used.

Homeless people often lack the IT knowledge and skills necessary to access the Internet, which can inhibit use. If people have not previously had access to, or lack an awareness of or interest in the Internet, its potential as a resource is not recognized and leads to ambivalence. One respondent claimed, "It's such an extraordinary resource but not if you can't even grasp what these things do!" Having the literacy, numeracy and IT skills necessary to access the Internet are crucial to how the tool comes to be used.

A thorough investigation of how homeless people domesticate information and communication technologies into their everyday lives, and how they attribute meaning to them, reveals how these technologies may influence their actions and activities.

\section{Digital Inclusion to Achieve Social Inclusion? Questioning Assumptions}

From the research conducted two things became clear: first, social inclusion and digital inclusion are not synonymous concepts (although they may be associated), and second, the varying uses and influences of mobile phones and the Internet require them to be considered separately rather than within the same category of information and communication technologies when studying how they affect homeless people's everyday lives. More specifically, ICTs seem to 'include' homeless people into their own local culture, rather than into mainstream society. 
Interestingly, the Internet was recognized by outreach workers as a tool to gain access to resources and information for their own purposes, but the connection was not made that this could be useful to homeless individuals, with the exception of using it for housing searches. This is likely because workers are more concerned with higher priority problems such as locating accommodation or food for their clients. With respect to mobile phones, however, outreach workers felt that digital inclusion held different implications. That is, they fully recognized that many homeless people have mobile phones, and "use them just like anybody else", implying that they are relatively 'digitally included' with respect to mobile telephony.

That digital inclusion leads to social inclusion is often a strongly held assumption within social inclusion policy initiatives in Britain. This is apparent in a quote by the Scottish Executive in the same report mentioned earlier:

In a digitally-inclusive Scotland, the public, private and voluntary sectors will make positive use of digital technologies and the Web to improve quality of life and deliver new opportunities for disadvantaged individuals and communities (2001, p. 5).

However, as has been described, homeless individuals appropriate and domesticate technologies in ways that reinforce the patterns and practices of everyday lives, and therefore ICT access and capability alone will not change an individual's situation. Outreach workers and homeless and ex-homeless respondents alike tended not to reveal such a deterministic view. Indeed, they recognized that homeless people are relatively digitally included, particularly with respect to mobiles, while remaining socially excluded in many ways. Of course, there are positive aspects of ICT access. For example, one study about public Internet access found that ICT capability and confidence for using computers was built through 'local experts' acting as positive role models (Faulkner \& Kleif, 2003b).

It is clear that the complex concepts of digital inclusion and social inclusion are not synonymous. For some individuals, they can be mutually exclusive, a conclusion which can be drawn from the research in this study. It is interesting that homeless individuals themselves are aware that there is no clear deterministic link between social inclusion and digital inclusion, despite the fact that this un-questioned assumption is deeply embedded in some policy arenas of the public and private sectors.

\section{Digital Inclusion via the Internet?}

In examining any potential links between the use of information and communication technologies and social inclusion, mobile phones and the Internet need to be considered separately, since for homeless people these technologies hold different meanings, are used in different ways and have different consequences on their lives. With respect to the Internet, two factors may account for the fact that users may feel more 'included' when online: the anonymity of users in virtual domains, and the fact that users are not physically present, which allows individuals to withhold or manipulate any key features to their identity (Roberts \& Parks, 2001). In this way, homeless people can anonymously act out different identities, which may have an emancipating effect due to limited social repercussions of their actions online.

Social interactions 'online' may widen or stabilize the social networks of homeless individuals through the creation and maintenance of social contacts with others, via email or in chatrooms, for example. This may have profound implications for the social support networks of homeless people, such as for one homeless respondent who was keeping in touch via email with a friend who had recently returned to Cambodia. Outreach workers seemed to recognize the significance of inclusion into peer networks (and subsequent social habits) of local subculture, claiming that the key to helping clients is to quickly find accommodation for them before they become part of the subculture. This can help to avoid potentially damaging situations, such as intervening "before becoming really heavy into drug use" through contacts made with other homeless individuals, leading things to "go downhill really fast."

Not only can the Internet provide links with other people, but also to the 'information society', which can be a significant resource for those who are homeless. This is most useful for finding housing above all, since such a search is often more easily done via the Internet. Homeless, ex-homeless and outreach workers alike informed me that many homeless people use this searching method much more readily than other methods, provided they have the ICT capability and access to do so. For these reasons, some outreach workers are introducing clients to online housing application processes, which can provide homeless individuals with an appealing incentive to use the Internet for the first time. 
The usefulness of the Internet stems from how it is used to provide the appropriate information. One outreach worker described:

It's only as useful as people want it to be useful [...]. It can give people a focus, because it can connect people, but there has to be something there to start with ... but if it's available and instantly accessible, it can be another hook to engage people in whatever interests they have.

Thus, the resources and information that the Internet provides may help to facilitate an individual in changing their situation, but by no means can its usefulness be taken to imply that this alone can change a person's situation: the motivation stems from the individual.

\section{Digital Inclusion via Mobile Phone?}

Mobile phones, on the other hand, are much more easily appropriated into homeless subculture than the Internet. A number of service agencies in Edinburgh provide their homeless clients with mobile phones in order to keep in touch with them more easily. Service agencies are selective about who should receive mobiles, but it can be difficult to discern which homeless individuals could benefit most from having one. Those clients who do receive them tend to be "fairly stable and doing better, purely because it makes [the support worker's] job easier to assist them." This is because clients who are more chaotic tend to have a much higher mobile "turnover rate" making regular communication more difficult. As an example, one service organization gave a mobile phone to someone who had been a client for a number of years, who had begun studying, and was "totally clean" from using drugs. It was thought that he would find a mobile phone useful because "[life] is still a bit stressful for him." Interestingly, one outreach worker claimed that it is "still not the norm at all for outreach workers to ask for clients' mobile numbers... It's just not something that occurs to me as a worker." This is most likely because mobile contact is still not fully 'embedded' within the services a homelessness agency provides. It is as if giving a client a mobile phone justifies communication between worker and client via that medium, since those who do not tend to receive mobile phones from service agency workers are also less reliable with their phones.

According to outreach workers, the benefits of contacting clients via mobile phone are many: "It's a lifeline, most certainly [...] and they just make our lives much easier as well. It is, from my point of view, invaluable." For support workers, mobile phones are useful for immediately contacting clients to see how they are doing through a phone call or text message. One worker, for example, described how he calls his clients who have mobiles every morning, "especially on Mondays, because there is always some chaos going on then; because there is not enough support on the weekends." Those clients without mobiles he goes to see in person ${ }^{6}$. The knowledge of a client's immediate situation allows workers to provide more immediate support, which is important, since the lives of many homeless people are planned on a very minute-to-minute basis. Mobile contact between workers and clients also "saves time, money and resources in every respect", from a service agency point of view. Further implications will be discussed in more depth in the next section.

It is clear that mobile phones can facilitate processes towards social inclusion; they may assist those individuals who are trying to improve their lives, but for those whose situations are unchanging or worsening, having a mobile may lead to the proliferation of problems by reinforcing a chaotic lifestyle. Whether a homeless person wishes to use a mobile phone to contact a worker, or to deal drugs, in either sense it is a useful tool. Interestingly, outreach workers seem to turn a blind eye to the 'undesirable uses' to which a mobile phone is put by a homeless person. Yet, as described by a worker, if mobiles "serve a purpose for us in terms of getting in touch with our clients, and our clients being in touch with us, regardless of whether we buy the phone or not, they're gonna get a phone and abuse that anyway."

Mobile phones are also an important medium, and sometimes the only one, for keeping in touch with friends and family. Naturally, homeless and ex-homeless respondents who own mobile phones use them to contact specific people they were already in contact with, thereby enhancing their communication with those individuals. However, the social benefits here should not be overstated, since specific problems like low battery power or credit balance can hinder ease of communication. As one respondent described,

\footnotetext{
${ }^{6}$ Two things become apparent here: first, that clients seem to get more 'chaotic' when support agencies are closed; and second, that support workers with clients who own mobile phones see them less frequently in person, the implications of which will be examined later.
} 
"there are certain types of people who have mobiles", and those tend to be the people with families or networks of friends. In contrast to the use of the Internet, it did not emerge in this study that homeless people used mobiles to help them find housing.

Generally, how mobile phones and the Internet come to be used by homeless people depends on the stability and the motivations of the individual, which in turn influence how the technology further becomes used in the activities of everyday life. That is, individuals who are more stable tend to find ICTs useful to facilitate inclusion through access to 'positive' social networks, for example, while more unstable or chaotic homeless people might use ICTs as tools to communicate while committing crimes. Furthermore, it is clear that ICTs alone do not provide an avenue to social inclusion, although they may have positive implications, since the routes to normative inclusion into the activities of mainstream society are much more complex.

\section{Implications of Mobile Phone Use in Social Service Delivery}

Increased contact via mobile telephony between clients and workers can have profound implications for homeless clients, as well as for social service delivery processes. One major issue is the reliance or dependency on the communication technology by workers and clients alike. For one worker, "It's a double-edged sword" because on one hand, communication is facilitated, but on the other hand, clients may be depended on too much for having their phones on and working. Also, if help is more immediate when an outreach worker can be directly contacted, the needs of a homeless person can be more quickly satisfied instead of requiring them to sort out arising dilemmas alone. This could have a significant effect on the client-worker relationship, since the primary aim of most outreach workers is to build a trusting relationship with each client. It could also lead a homeless individual to rely less on their own means to solve a situation. Clearly, having a mobile seems to facilitate how a homeless person wishes to live their life but again, this stems from how a technology is used.

Another implication is that workers may see those clients with mobiles less frequently in person, although no strict generalizations should be made here. For example, one outreach worker claimed to see a particular client more often in person even though that individual owned a mobile phone, claiming the reason was "just because of the nature that he is, I suppose it's nothing to do with the mobile phone." Nevertheless, less face-to-face contact can have serious repercussions for clients. One outreach worker voiced her concern:

There's just something about spending time with someone, it just seems to make a difference. But probably because when you're spending time with someone you're trying to achieve something, or doing something that they appreciate in the end.

It is possible that with an increased reliance on mobile phones, less face-to-face contact can have profound implications for workers helping clients. For clients, too much reliance on mobile phones by support workers can therefore be detrimental; yet in the face of organization budget cuts, for example, it is a realistic compromise.

Aside from the larger structural problems in post-industrial societies leading to homelessness, an overreliance on ICTs can also be a problem since homeless people may depend more on their support workers rather than their own resources to solve problems, which may stunt the development of individual agency necessary for social inclusion to occur. In this sense, clients may feel less accountable for their actions, since they know they can get in touch with their workers, and vice versa, at any time. For clients, mobile phones are useful to maintain a higher amount of contact with service agencies, because homeless people are "relatively disengaged with services."

Another important implication is that clients may be less likely to be cut off from service organizations, because they can easily contact their worker to cancel or postpone an appointment. Otherwise, in some Scottish service agencies, clients may be cut off from help after missing a certain number of appointments without giving notice. The personal and bureaucratic implications of this increased client-worker contact are significant, since help is more immediate and readily available.

Clearly, this is an issue that deserves further study in relation to social service delivery, particularly if other social service agencies are considering giving their clients mobile phones. 


\section{Conclusions}

Technologies are intricately woven into the social fabric of our everyday lives; and therefore studying technology and its shaping effects on humans is imperative to the study of human social change. It is important to look at various uses and meanings that mobile phones and the Internet hold for homeless people, and the resulting implications this may have on their lives. Digital inclusion is often expressed as synonymous with social inclusion, with the deterministic assumption that one process can lead to the other. However, this study reveals that people who are homeless can be relatively digitally included, especially with respect to mobile phones, while remaining socially excluded ${ }^{7}$. Even if homeless people can more easily find housing using the Internet, for example, other problems (such as chronic unemployment, family crises or inadequate life skills) may continue to prevail, and so they can still be vulnerable to homelessness. Similarly, access and use of ICTs can facilitate the everyday activities and communication within homeless subculture. Contact is thereby maintained or strengthened between excluded individuals, possibly including drug dealers or law-breaking individuals, which can encourage criminal activities even in such severe cases as committing a rape crime. Additionally, homeless people may appreciate contact with family or friends, but this again may involve being in touch with people who have similar social and economic problems, rather than with individuals who can provide more complex levels of support needed by homeless individuals to improve their situations. The lack of access to formal social networks that can help people to alleviate problems may therefore not be achieved. Again, generalizations cannot be made here, as for example, one homeless respondent described how his (socially and economically stable) sister gave him a mobile phone so that she could easily reach him when she needed him to mind her children. Access and use of ICTs can provide homeless people with IT or communication skills, which can be beneficial, but it is the uses to which these skills are put which determine if social inclusion is to be achieved.

Even for those homeless individuals who seem relatively digitally included on the surface - through relatively regular access to the Internet, and ownership and use of a mobile phone - this 'digital inclusion' is not characterized in the same ways as digital inclusion for someone who is socially included. For example, homeless people who own and use mobiles find it difficult to keep them from being stolen, or from trading, selling or losing them. Simply keeping mobiles functioning is also found to be difficult due to energy charging and credit struggles. Likewise, communication via the Internet is often difficult, for example, when an email account is accessed so sporadically that passwords are regularly forgotten. For these reasons, it is difficult for homeless people to consistently rely on these technologies to provide them with a permanent address even in 'cyberspace'. People who are homeless continue to be excluded, both physically from institutions (other than service agencies) and practically, from the life skills needed to be self-sufficient enough to live in permanent accommodation.

Although social inclusion has not been shown to result from digital inclusion with respect to homeless people in this study, it is important to note that information and communication technologies were helpful for those people who choose to change their lives for the better; those who are trying to become more stable socially, economically, physically and emotionally. At this point, ICTs can facilitate a move towards stability, by providing access to communication and information paths. It is clear that more research needs to be done to more fully understand when technologies may help to bridge inclusion into mainstream society, or when they are used as a link to homeless subculture.

The route to social inclusion is in actuality very complex, and requires many more factors than access, use and ICT capability (or digital inclusion), such as a stable social and economic environment and the desire and motivation for change. If we wish to eradicate the most glaring inequalities that prevail in modern society, therefore, we need to look farther than the provision of access to information and communication technologies and the skills to use them, and beyond the deterministic view that technology will have only positive benefits on the path to mainstream participation. New digital technologies are instead a new, complicating factor that must be taken into account in the overall process of helping disadvantaged individuals to change their lives for the better.

\footnotetext{
${ }^{7}$ It must be kept in mind that no strict generalizations can be made from the relatively small, qualitative sample size of this pilot study.
} 


\section{References}

Atkinson, A. B. (1998). Social exclusion, poverty and unemployment. CASE Paper: Exclusion, Employment and Opportunity, 4, 1-20.

Ballintyne, S. (1999). Unsafe streets: Street homelessness and crime. London: Institute for Public Policy Research.

Banyard, V.L. \& Miller, K.E. (1998). The powerful potential of qualitative research for community psychology. American Journal of Community Psychology, 26(4), 485-505.

Bijker, W. E., Hughes, T. P. \& Pinch, T. (1987). The social construction of technological systems. Cambridge, MA: MIT Press.

Edinburgh Cyrenians. (2001). Understanding homelessness. Retrieved June 25, 2003 from http://www.cyrenians.org.uk/ezedit/view.asp?MID=212

Faulkner, W. \& Kleif, T. (2003a). One size does not fit all! Digital in/exclusion in a rural community. SIGIS case study report. Edinburgh: University of Edinburgh.

Faulkner, W. \& Kleif, T. (2003b). Included women, excluded men: Users and non-users of rural community resource centres. SIGIS user study report. Edinburgh: University of Edinburgh.

Ferlander, S. \& Timms, D. (1999). Computer-supported community networks and social cohesion. SCHEMA: Social cohesion through higher education in marginal areas. Retrieved July 2, 2003 from http://www.stir.ac.uk/schema/conf/LocalNets/Italy.pdf

Forrest, R. (1999). The new landscape of precariousness. In P. Kennett \& A. Marsh, (Eds.), Homelessness: Exploring the new terrain (pp. 17-36). Bristol: Policy Press.

Fortunati, L. \& Manganelli, A. (2002). A review of the literature on ICT in Italy. SIGIS Report. METIS Centre: Italy.

Glasser, I. \& Bridgman, R. (1999). Braving the street: The anthropology of homelessness. Oxford: Berghahn.

Henwood, F., Wyatt, S., Miller, N. \& Senker, P. (2000). Critical perspectives on technologies, in/equalities and the information society. In S. Wyatt, F. Henwood, N. Miller \& P. Senker, (Eds.), Technology and in/equality: Questioning the information society (pp. 1-18). London: Routledge.

Katz, J. E. \& Aakhus, M. (2002). Introduction: Framing the issues. In J. E. $\quad$ Katz \& M. Aakhus, (Eds.), Perpetual contact: Mobile communication, private talk, public performance (pp. 1-13). Cambridge, UK: Cambridge University Press.

Lefevbre, H. (1971). Everyday life in the modern world. London: Allen Lane.

Lie, M. \& Sørensen, K. H. (1996). Making technology our own? Domesticating technology into everyday life. Oxford: Scandanavian University Press.

Livingstone, S. (1992/1994). The meaning of domestic technologies: A personal construct analysis of familial gender relations. In R. Silverstone and E. Hirsch, (Eds.), Consuming technologies: Media and information in domestic spaces (pp. 113-130). London: Routledge.

MacKenzie, D. \& Wajcman, J. (1985/2002). Introductory essay: The social shaping of technology. In D. MacKenzie and J. Wajcman, (Eds.), The social shaping of technology (pp. 3-27). Buckingham: Open University Press.

McIntosh, I. \& Erskine, A. (1999). "I feel rotten. I do, I feel rotten": Exploring the begging encounter. In H. Dean, (Ed.), Begging questions: Street-level economic activity and social policy failure (pp. 183202). Bristol: Policy Press.

Ravenhill, M. (2000). Homelessness and vulnerable young people. CASE paper, 37, 1-76. 
Richardson, L. \& Le Grand, J. (2002). Outsider and insider expertise: The response of residents of deprived neighbourhoods to an academic definition of social exclusion. CASE paper, 57, 1-29.

Roberts, L. D. \& Parks, M. R. (2001). The social geography of gender-switching in virtual environments on the Internet. In E. Green \& A. Adam, (Eds.), Virtual gender:

Technology, consumption and identity (pp. 265-287). London: Routledge.Scottish Executive. Digital inclusion: Connecting Scotland's people. (2001). Retrieved on July 2, 2003, from http://www.scotland.gov.uk/library3/enterprise/dics-00.asp

Shaw, I., Bloor, M. \& Roberts, S. (1996). Without shelter: Estimating rooflessness in Scotland. Edinburgh: The Scottish Office Central Research Unit.

Silver, J. (1996). Libraries and the homeless: Caregivers or enforcers. The Katharine Sharp Review. Columbia: University of South Carolina, 7-14.

Silverstone, R., Hirsch, E. \& Morely, D. (1992/1994). Information and communication technologies and the moral economy of the household. In R. Silverstone \& E. Hirsch, (Eds.), Consuming technologies: Media and information in domestic spaces (pp. 15-31). London: Routledge.

Stewart, J. (2003). The social consumption of information and communication technologies (ICTs). Cognition, Technology and Work, 5, 4-14.

Sørensen, K. (2002). Love, duty and the S-curve: An overview of some current literature on gender and ICT. SIGIS report. Edinburgh: University of Edinburgh.

Thomas, G. and Wyatt, S. (2000). Access is not the only problem: Using and controlling the Internet. In S. Wyatt, F. Henwood, N. Miller \& P. Senker, (Eds.), Technology and in/equality: Questioning the information society (pp. 21-45). London: Routledge.

Vestby, G. M. (1996). Technologies of autonomy? Parenthood in contemporary "modern times." In M. Lie \& K. H. Sørensen, (Eds.), Making technology our own? Domesticating technology into everyday life (pp. 65-90). Oxford: Scandanavian University Press.

Williams, R., Slack, R. \& Stewart, J. (2000). Social learning in multimedia. SLIM Final Report. Edinburgh: University of Edinburgh. 


\section{Appendix}

\section{Interview 1}

This interview was conducted with a volunteer in her early 20 s at a local organization for homeless people in Edinburgh city centre. It housed a scanner, printer and one computer with Internet access, provided specifically for homeless individuals. Also in the same location were laundry facilities and a second-hand clothing shop. The service organization was part of a larger umbrella organization which provided advice and support services for homeless people in Edinburgh.

\section{Interview 2}

This interview was begun with a supporting persons' worker in her early 30s at an Edinburgh homeless outreach centre. After approximately 15 minutes, she was replaced by a male colleague in his early 40s, since she needed to attend to a client immediately. The centre was geared towards those who are vulnerably housed or have a long history of homelessness (with a varied client base). Both interviewees worked with each of their clients using an individually-centered approach, between 15 to 20 hours per week with the aim to build a trusting relationship with each client, helping them to gain independence, and build confidence and self-esteem.

\section{Interview 3}

This interview took place at an internet café for homeless people in Glasgow with the internet café tutor/ supervisor/ manager, an ex-homeless female in her mid-40s. The internet café contained approximately 10 computers with broadband Internet access, as well as access to basic online computer courses and a network of learning centres where one-on-one computer support was readily available.

\section{Interview 4}

This interview was conducted in a public café in the centre of Edinburgh with a man in his late 40s who had been homeless for the past 20 years at the time of the interview. Throughout that time he had slept rough (in the outdoors and in derelict housing), and had lived in various temporary residences and tenancies. At the time of the interview he had been living in a hostel for the past 2 years. He was a wellspoken homelessness advocate and campaigning activist, a trustee for 3 other local organizations as well as an employee of the Big Issue homelessness magazine.

\section{Interview 5}

This interview was conducted at the University of Edinburgh with a senior outreach worker in her late 30s. She worked with the homeless addictions team as part of the homeless outreach project, like the respondents in Interview 2. As part of the harm reduction program, a major part of her job was to make a daily route around the city looking for homeless individuals who were begging, letting them know where they can get help at local services, giving out clean needles and methadone prescriptions among other things. Her contact with homeless clients was regular in order to build trusting relationships.

\section{Interview 6}

This interview was conducted with a senior outreach worker in his mid-to-late $40 \mathrm{~s}$ at an organization which housed 8 community-based programs for various groups of marginalized and excluded people. Like the other outreach workers I interviewed, he was highly familiar with 'severe' homeless issues.

\section{Interview 7}

This was an informal focus group that was held with two homeless individuals at the internet café for homeless people in Glasgow. Both respondents were able to give an in-depth account of how homeless people use the Internet for two reasons: they were both 'regulars' in the internet café, and therefore had a good idea of how the computers were used; and because it is the only location with multiple Internet access points specifically for homeless people in Scotland. With respect to mobiles, both respondents also had a good idea of how homeless people use them, although this topic was not seen as particularly interesting to them. 


\section{Interview 8}

This was a focus group held with five homeless and ex-homeless youth (four male and one female), all between the ages of 16 and 25. The interviewees had each "grown up in care" (in bed-sits or foster homes) but none were sleeping rough. The focus group was held at an umbrella organisation for voluntary organisations in Edinburgh and the Lothian regions that worked with homeless people between the aforementioned ages.

\section{Interview 9}

This interview was held with two ex-homeless volunteers at the same organization as in Interview 1. The first interviewee was an older (mid 40s) ex-hard drug user, and the second was a 16-year old youth. 